\title{
Efek vortex generators terhadap peningkatan perpindahan panas pada aliran melewati heated tubes
}

\author{
Yafid Effendi ${ }^{*}$, Ali Rosyidin² \\ 1,2Program Studi Teknik Mesin, Fakultas Teknik, Universitas Muhammadiyah Tangerang \\ Jl. Perintis Kemerdekaan I/33 Cikokol-Tangerang \\ *Corresponding author: yafid_effendi@yahoo.com
}

\begin{abstract}
In this decade, improving the rate of heat transfer has become a big challenge. The high thermal resistance of the gas side of the heat exchanger has an impact on the low rate of heat transfer. Therefore, an experimental study was carried out aimed at looking at conditions of hot temperature and decreased air flow pressure through a heated tube in a rectangular channel using artificial surfaces, namely the concave delta winglet and delta winglet vortex generators. Concave delta winglet vortex generators (CDW VGs) are installed in-line and staggered with one, and two pairs are arranged in common-flow-down (CFD) in the direction of flow with an angle of attack of $15^{\circ}$. The experimental results show that the best thermal performance is observed in the use of two rows CDW VGs staggered, where the value of performance evaluation criteria (PEC) is $28.88 \%$ higher than the use of CDW VGs in-line, DW VGs staggered and DW VGs in-line at the same Reynolds number. At the same Reynolds number, the Nusselt number ratio and the friction factor ratio increased $45.25 \%$ and $152.05 \%$ respectively, occurring in two rows of CDW VGs staggered compared to other vortex generators.
\end{abstract}

Keywords: vortex generators, heat transfer, Nusselt number, friction factor, PEC.

\begin{abstract}
Abstrak
Pada dekade ini, perbaikan laju perpindahan panas menjadi tantangan yang besar. Tingginya hambatan termal dari sisi gas pada heat exchanger berdampak pada rendahnya laju perpindahan panas. Oleh karena itu, studi eksperimen dilakukan bertujuan untuk mengetahui peningkatan koefisien perpindahan panas konveksi dan penurunan tekanan aliran udara melewati heated tube di dalam saluran rectangular menggunakan permukaan buatan yaitu concave delta winglet dan delta winglet vortex generators. Concave delta winglet vortex generators (CDW VGs) dipasang in-line dan staggered dengan satu, dan dua pasang disusun dalam common-flow-down (CFD) pada arah aliran dengan sudut serang $15^{\circ}$. Hasil eksperimen menunjukkan bahwa performa termal terbaik teramati pada penggunan dua baris CDW VGs staggered, yang mana nilai performance evaluation criteria (PEC) adalah $28.88 \%$ lebih tinggi daripada penggunaan CDW VGs in-line, DW VGs staggered dan DW VGs in-line pada Reynolds number yang sama. Pada Reynolds number yang sama, rasio Nusselt number dan rasio faktor gesek meningkat berturut-turut $45.25 \%$ dan $152.05 \%$ terjadi pada dua baris CDW VGs staggered dibandingkan dengan vortex generators yang lain.
\end{abstract}

Kata kunci: vortex generators, perpindahan panas, Nusselt number, faktor gesek, PEC.

\section{Pendahuluan}

Kondisi iklim Indonesia yang tropis berakibat pada tingginya kebutuhan udara nyaman bagi masyarakat. Hal ini mendorong peningkatan permintaan unit air conditioning (AC) untuk rumah tangga.
Pada tahun 2019 diperkirakan 20 juta unit $\mathrm{AC}$ residential telah terpasang di rumah tangga [1]. Berdasarkan fakta ini, peningkatan efisiensi energi pada $\mathrm{AC}$ rumah tangga menjadi topik yang menarik untuk dikaji. Peningkatan efisiensi ini dapat 
dilakukan dengan mempertinggi laju heat transfer dari salah satu komponen utamanya, seperti contohnya kondensor. Kondensor pada unit AC rumah tangga biasanya dari jenis heat transfer fin and tube yang mana udara digunakan sebagai media pendingin refrigeran. Tingginya hambatan termal sisi udara pada kondensor menyebabkan rendahnya laju heat transfer [2].

Oleh karena itu, peningkatan laju heat transfer sisi udara pada kondensor menjadi topik yang menarik untuk diinvestigasi dalam peningkatan performa termal. Peningkatan performa termal dapat dilakukan melalui metode aktif dan metode pasif. Metode aktif membutuhkan energi dari luar seperti medan listrik, surface vibration, dan lainnya. Sedangkan metode pasif tidak memerlukan energi dari luar, namun metode ini memerlukan modifikasi pada permukaan heat transfer dengan menggunakan vortex generators sebagai salah satu contohnya [3].

Vortex generators merupakan salah satu metode aktif yang efektif untuk mempertinggi koefisien heat transfer konveksi sisi udara dari sebuah kondensor karena vortex generators dapat memproduksi aliran turbulen dan mengganggu perkembangan lapisan batas termal [4-7]. Mekanisme perbaikan heat transfer yang diakibatkan oleh pemasangan vortex generators adalah pembangkitan longitudinal vortex yang menghasilkan gerakan swirling, mengganggu pertumbuhan lapisan batas termal, membawa panas dari dinding ke inti aliran [8-9].

Keuntungan penggunaan vortex generators dalam peningkatan heat transfer telah banyak diteliti oleh para peneliti baik secara eksperimen dan numerik. Liu et al. [11] menginvestigasi susunan vortex genertors pada permukaan fin dengan sepuluh delta winglet vortex generators mengelilingi tubes untuk perbaikan heat transfer. Hasil studi mereka menunjukkan reduksi area wake di belakang tube oleh karena penggunaan vortex generators dan peningkatan pencampuran fluida panas dan dingin, serta peningkatan jumlah vortisitas. Song et al. [12] mempelajari karakteristik heat transfer dengan berbagai penggunaan geometri optimal vortex generators jenis concave dan convex dalam saluran plat heat transfer pada kondisi laminar yang mana peningkatan performa heat transfer tertinggi didapati pada penggunaan concave vortex generators. Huang and Chiang [13] mempelajari bentuk desain optimal dan posisi untuk penggunaan delta winglet vortex generators pada pin-fin heat sinks untuk meningkatkan performa pendinginan yang terbaik. Lotfi et al. [14] meneliti secara numerik performa thermo-hydraulic dengan menggunakan smooth wavy fin-andelliptical tube heat transfer menggunakan type rectangular trapezoidal winglet (RTW), angle rectangular winglet (ARW) and curved angle rectangular winglet (CARW).

Syaiful dkk., 2016 [15] melakukan eskperimen untuk mengetahui efek geometri dan jumlah vortex generators tipe rectangular winglet dan concave rectangular winglet terhadap koefisien heat transfer konveksi. Hasil penelitian menunjukkan bahwa 3 baris concave rectangular winglet menghasilkan koefisien heat transfer paling tinggi. Nusselt number dan j-factor meningkat sebesar 205\%, sementara tahanan termal menurun sebesar $67 \%$ dibandingkan dengan baseline (tanpa vortex generators) pada Reynolds number yang paling tinggi.

Beberapa literatur tersebut menunjukkan bahwa bentuk geometri VG memiliki pengaruh signifikan terhadap peningkatan perpindahan panas dan pressure drop. Namun demikian, penelitian tentang penggunaan CDW VGs terhadap peningkatan performa perpindahan panas pada aliran udara yang melewati silinder panas masih belum banyak dilakukan. Oleh karena itu, penelitian ini dilakukan untuk meningkatkan perpindahan panas dengan vortex generators (VGs). 


\section{Metode Penelitian}

Penelitian ini menggunakan metode eksperimen, pengujian dilakukan di dalam sebuah saluran udara yang terbuat dari kaca dengan ketebalan $10 \mathrm{~mm}$, panjang $370 \mathrm{~cm}$, lebar $8 \mathrm{~cm}$, dan tinggi $18 \mathrm{~cm}$. Saluran udara ini memiliki penampang berbentuk persegi panjang yang dilengkapi dengan fan, hot wire anemometer, pitot tube, micromanometer, pemanas, kompresor, laser, pipa kapiler, motor regulator. Kecepatan udara divariasikan $0.4 \mathrm{~m} / \mathrm{s}-2$ $\mathrm{m} / \mathrm{s}$ melewati enam tube dengan panas konstan 35 W. Daerah pada pengujiadn dibagi atas empat bagian, yaitu: inlet, straightener, test section, dan outlet. Skema alat pengujian tampak pada Gambar 1.

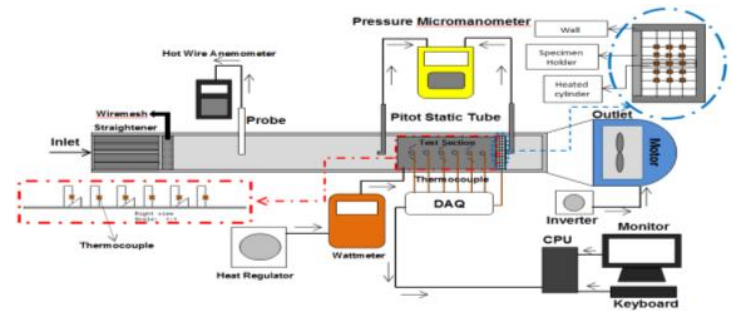

Gambar 1. Skema alat pengujian

Pada pengujian ini, benda uji yang digunakan adalah concave delta winglet vortex generators (CDW VGs) dan delta winglet vortex generators (DW VGs) dengan tube yang dipanaskan. Benda uji dapat dilihat pada Gambar 2.
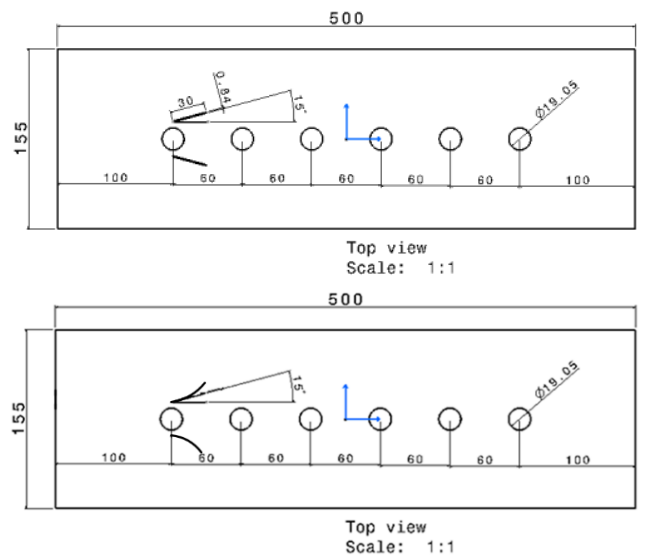

Gambar 2. Delta winglet dan concave delta vortex generator (satuan dalam $\mathrm{mm}$ )

Variasi dalam penelitian ini delta winglet in-line satu, dan dua pasang, delta winglet staggered satu, dan dua pasang, concave delta winglet in-line satu, dan dua pasang dan concave delta winglet staggered satu, dan dua pasang seperti pada Gambar 3, 4, 5, dan 6 . (a)

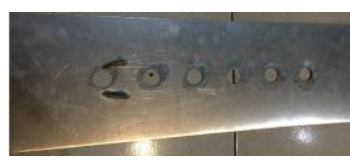

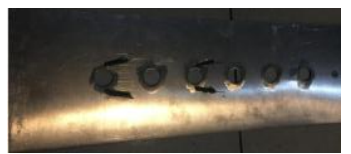

(b)

Gambar 3. Delta winglet vortex generators (a) inline satu pasang, (b) in-line dua pasang

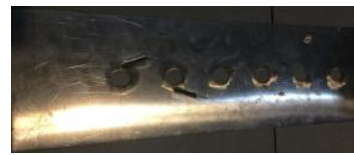

(b)
Gambar 4. Delta winglet vortex generators (a) staggered satu pasang, (b) staggered dua pasang

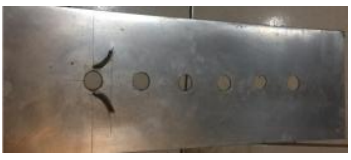

(a)

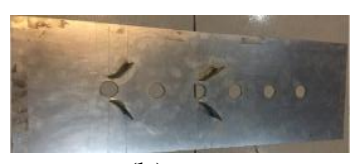

(b)
Gambar 5. Concave delta winglet vortex generators

(a) in-line satu pasang, (b) in-line dua pasang

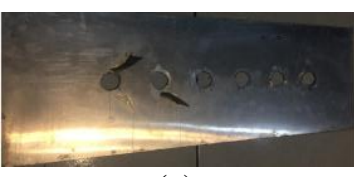

(a)

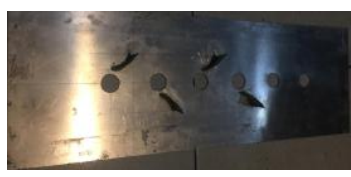

(b)
Gambar 6. Concave delta winglet vortex generators (a) staggered satu pasang, (b) staggered dua pasang

Reynoldss number $(\mathrm{Re})$ didefinisikan:

$$
R e=\frac{\rho U D_{h}}{\mu}
$$

Dengan $\rho$ densitas $\left(\mathrm{kg} \cdot \mathrm{m}^{-3}\right)$, U kecepatan $\left(\mathrm{ms}^{-1}\right)$, D diameter hidrolik saluran udara (m), and $\mu$ viskositas dinamik (Pa.s). Diameter hidrolik saluran udara dapat dihitung $D_{h}=\frac{4(a b)}{2(a+b)}$.

Dengan $\mathrm{Nu}$, Nusselt number

$$
N u=\frac{h D_{h}}{k}
$$

Berikut rumus Darcy-Weisbach, friction factor adalah:

$$
f=\frac{2 D_{h} \Delta P}{\rho U^{2} L}
$$

Performance evaluation criteria (PEC) digunakan sebagai kriteria penilaian untuk mengevaluasi peningkatan heat transfer pada penelitian silinder yang dipanaskan dengan vortex generators. PEC [10] ini 
ditentukan oleh bilangan Nusselt dan faktor gesekan sebagai berikut:

$$
P E C=\frac{N u / N u_{0}}{\left(f / f_{0}\right)^{\frac{1}{3}}}
$$

tanda 0 artinya nilai tanpa vortex generators (baseline).

\section{Hasil dan Pembahasan}

\section{Perbandingan performa heat transfer}

Karakteristik heat transfer untuk CDW VGs satu, dan dua pasang dan DW VGs satu, dan dua pasang, keduanya disusun in-line dan staggered dibandingkan dengan baseline ditunjukkan pada Gambar 8 dan Gambar 9. Gambar 8 menunjukkan Nusselt number meningkat dengan meningkatnya Reynolds number untuk kasus yang menggunakan vortex generators. Gambar 8 diperoleh bahwa Nusselt number untuk kasus yang menggunakan vortex generators jenis CDW in-line dan staggered mempunyai nilai yang lebih besar dibandingkan dengan kasus yang menggunakan VG jenis DW [18]. Pada Re 9000, nilai perbandingan Nusselt number mengalami kenaikan $13.08 \%, 16.83 \%$, $32.62 \%$ dan $35.99 \%$ saat menggunakan DW VGs in-line, DW VGs staggered, CDW VGs in-line dan CDW VGs staggered dibandingkan dengan baseline. Ketika menggunakan CDW VG, longitudinal vortex yang terbentuk berdiameter lebih besar dan lebih kuat dibandingkan dengan longitudinal vortex yang terbentuk dari DWP VG.

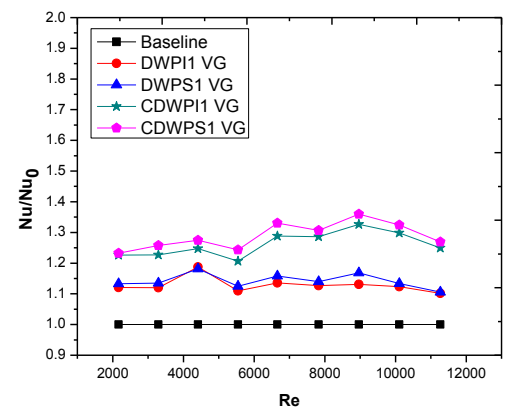

Gambar 8. Perbandingan Nusselt number DW VG dan CDWP VG satu pasang in-line dan staggered terhadap baseline untuk variasi Reynolds number

Gambar 9 menerangkan rasio Nusselt number untuk kasus dengan menggunakan DW VGs dan CDW VGs dua pasang in-line dan staggered dibandingkan dengan baseline. Sama halnya dengan Gambar 8, bahwa rasio Nusselt number untuk kasus dengan menggunakan vortex generators jenis CDW mempunyai nilai yang lebih tinggi dibandingkan dengan kasus yang menggunakan VG jenis DW untuk Re yang sama. Rasio Nusselt number meningkat dengan meningkatnya Reynolds number untuk kasus yang menggunakan VG. Nilai tertinggi rasio $\mathrm{Nu}$ ketika menggunakan CDW VGs staggered, diikuti CDW VGs in-line, DW VGs staggered dan terakhir DW VGs in-line dibandingkan dengan baseline adalah 45.25\%, 40.91\%, 29.82 dan $28.29 \%$ pada Re yang sama.

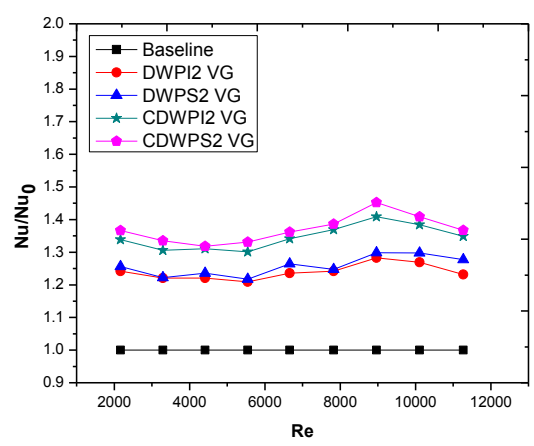

Gambar 9. Perbandingan Nusselt number rasio DWP dan CDWP VGs dua pasang terhadap baseline untuk variasi Reynolds number

2. Perbandingan performa faktor gesek

Gambar 10 dan Gambar 11 menunjukkan rasio faktor gesek untuk semua kasus. Rasio faktor gesek menurun dengan meningkatnya Reynolds number untuk kasus yang menggunakan vortex generators [10]. Sementara itu, rata-rata rasio faktor gesek pada Reynolds number yang sama untuk kasus DW VGs in-line, DW VGs staggered, CDW VGs in-line dan CDW VGs staggered adalah $25.96 \%$, $51.82 \%, 89.85 \%$, dan $108.67 \%$ lebih tinggi dibandingkan dengan baseline, seperti pada Gambar 11. Perbandingan faktor gesek antara DW VGs dan CDW VGs dua pasang in-line dan staggered tampak pada Gambar 12. Gambar 12 menunjukkan nilai rasio faktor gesek lebih besar untuk kasus dengan menggunakan vortex generators jenis CDW dibandingkan dengan kasus yang 
menggunakan $\mathrm{VG}$ jenis DW. Nilai rasio faktor gesek tertinggi $152.05 \%$ CDW VGs staggered, $146.05 \%$ CDW VGs in-line, $64.35 \%$ DW VGs staggered, dan $44.41 \%$ DW VGs in-line dibandingkan dengan baseline. Hasil perbandingan mengindikasikan rasio faktor gesek untuk konfigurasi concave delta winglet lebih besar daripada konfigurasi delta winglet pada Reynolds number yang sama.

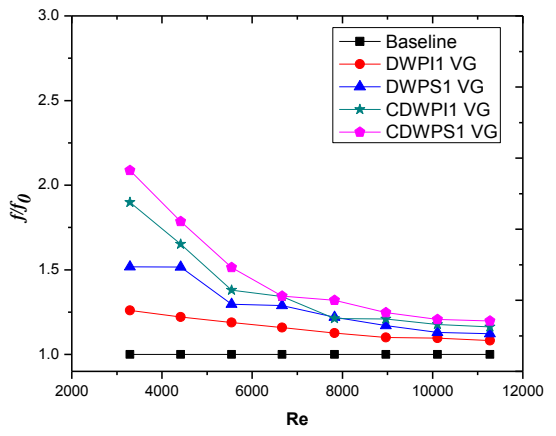

Gambar 10. Perbandingan faktor gesek rasio DWP dan CDWP VGs satu pasang terhadap baseline untuk variasi Reynolds number

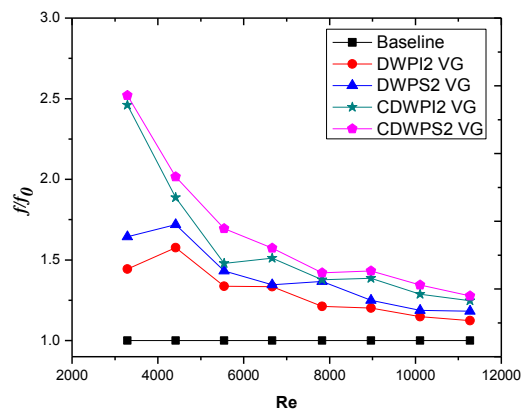

Gambar 11. Perbandingan faktor gesek rasio DWP dan CDWP VGs dua pasang terhadap baseline untuk variasi Reynolds number

\section{Perbandingan performa heat transfer}

Seperti yang disebutkan, faktor gesek akan meningkat dengan meningkatnya heat transfer. Karenanya, penting untuk membandingkan performa peningkatan heat tranfer. $\mathrm{Di}$ dalam penelitian, $P E C$ melibatkan faktor $N U$ dan $f$ digunakan sebagai kriteria penilaian untuk mengevaluasi peningkatan heat transfer untuk kasus ini. Perbandingan hasil untuk PEC ditunjukkan pada Gambar 12 dan Gambar 13. Performa termal meningkat dengan meningkatnya Reynolds number untuk kasus yang menggunakan vortex generators. Pada Reynolds number 9000, nilai tertinggi performa termal terjadi pada vortex generator jenis CDW staggered $26.34 \%$, diikuti CDW in-line $24.46 \%$, DW staggered $10.87 \%$ kemudian DW in-line 9.54\% dibandingkan dengan baseline, tampak pada Gambar 12. Gambar 13 menerangkan rasio performa termal untuk kasus dengan menggunakan DW dan CDW VGs dua pasang in-line dan staggered. Gambar 13 memperlihatkan nilai performa termal ketika menggunakan CDW VGs staggered, CDW VGs in-line, DW VGs staggered dan DW VGs in-line dibandingkan dengan baseline adalah $28.88 \%$, 26.39\%, 20.51\% dan $20.67 \%$ pada Reynolds number yang sama. PEC untuk kasus dengan menggunakan vortex generators jenis CDW in-line dan staggered mempunyai nilai yang lebih besar dibandingkan dengan kasus yang menggunakan VG jenis DW. Kita bisa lihat jelas untuk kasus CDW VGs staggered mempunyai performa termal terbaik, diikuti kasus CDW VGs in-line, DW VGs staggered dan DW VGs in-line.

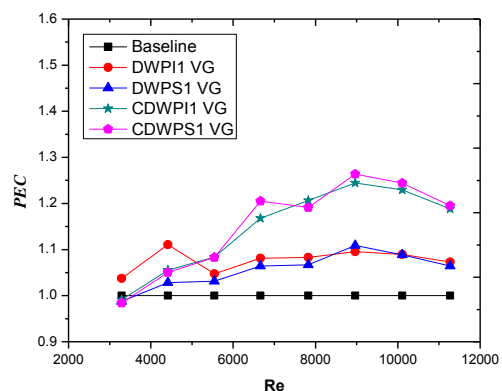

Gambar 12. Perbandingan peningkatan performa rasio DWP dan CDWP VGs satu pasang terhadap baseline untuk variasi Reynolds number

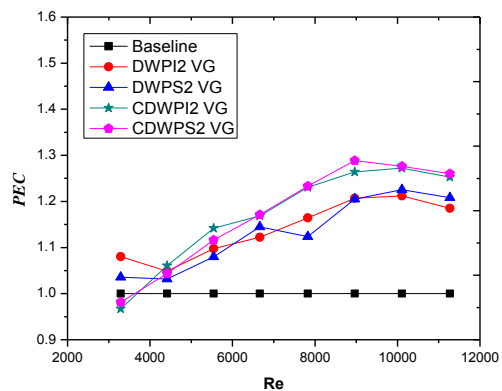

Gambar 13. Perbandingan peningkatan performa rasio DWP dan CDWP VGs dua pasang terhadap baseline untuk variasi Reynolds number 


\section{Kesimpulan}

Penelitian ini dilakukan secara eksperimen dengan membandingkan hasil eksperimen yang telah dilakukan oleh Stephen Whitaker. Ketika menggunakan vortex generators dapat meningkatkan performa termal. Efek peningkatan perpindahan panas dan pressure drop dapat disimpulkan sebagai bahwa performa termal terbaik ketika menggunakan 2 baris CDW VGs staggered dibandingkan dengan CDW VGs in-line, DW VGs staggered, dan DW VGs in-line pada Reynolds number yang sama. Nilai rasio $\mathrm{Nu}$ dan rasio faktor gesek tertinggi ketika menggunakan 2 baris CDW VGs staggered dibandingkan dengan CDW VGs in-line, DW VGs staggered dan DW VGs in-line. Jumlah baris vortex generators berpengaruh terhadap peningkatan perpindahan panas dan pressure drop.

\section{Ucapan terimakasih}

Penulis mengucapkan terima kasih atas bantuan dana hibah dari Ristekdikti dan juga laboran di Laboratorium Thermofluid UNDIP, departemen Teknik mesin Universitas Diponegoro dan prodi teknik mesin Universitas Muhammadiyah Tangerang, sehingga penelitian ini dapat diselesaikan.

\section{Referensi}

[1] http://ditjenppi.menlhk.go.id/beritappi/3407, diakses 28 Juli 2020, jam 13.00 WIB.

[2] M. Fiebig, A. Valencia, and N. K. Mitra 1993 Wing-Type Vortex Generators for Fin-and-Tube Heat transfers Exp. Therm. Fluid Sci. 7 287-295

[3] A. M. Jacobi and R. K. Shah 1995 Heat transfer Surface Enhancement through the Use of Longitudinal Vortices: A Review of Recent Progress Exp. Therm. Fluid Sci. 11 295-309

[4] M. Fiebig, 1998 Vortices, generators and heat transfer, Chem. Eng. Res. Des. 76 (2) 108-123
[5] G. Biswas, N.K. Mitra, M. Fiebig, Heat transfer enhancement in fin-tube heat transfers by winglet type vortex generators, Int. J. Heat Mass Transf. 37 (2) (1994) 283-291.

[6] G. Biswas, H. Chattopadhyay, A. Sinha, 2012 Augmentation of heat transfer by creation of streamwise longitudinal vortices using vortex generators, Heat Tran. Eng. 33 (4-5) 406-424.

[7] M. Awais, A.A. Bhuiyan, Heat transfer enhancement using different types of vortex generators (VGs): a review on experimental and numerical activities, Therm. Sci. Eng. Prog. 5 (2018) 524-545.

[8] G. Biswas, K. Torii, D. Fujii, K. Nishino, Numerical and experimental determination of flow structure and heat transfer effects of longitudinal vortices in a channel flow, Int. J. Heat Mass Transf. 39 (16) (1996) 34413451 .

[9] Vinicius Malatesta, Leandro F. Souza, Joseph T. C. Liu dan Markus J.Kloker, 2015, Heat transfer nalysis inaflow over concave wall with primary and secondary instabilities, Procedia IUTAM, vol.14, pp.487 - 495.

[10] L.H. Tang a, W.X. Chu b, N. Ahmed $b, M$. Zeng b. A new configuration of winglet longitudinal vortex generator to enhance heat transfer in a rectangular channel. Applied Thermal Engineering 104 (2016) 74-84

[11] Yuanbo Liu, Xuehu Ma $\square$, Xuan Ye, Yansong Chen, Yaqi Cheng, Zhong Lan. Heat transfer enhancement of annular finned tube exchanger using vortex generators: The effect of oriented functional circumferential arrangement. Thermal Science and Engineering Progress 10 (2019) 27-35

[12] Ke Wei Song, Toshio Tagawa, ZhongHao Chen, Qiang Zhang. Heat transfer characteristics of concave and convex curved vortex generators in the channel of plate heat transfer under laminar flow. International 
Journal of Thermal Sciences 137 (2019) 215-228

[13] Cheng-Hung Huang, Po-Ching Chiang. An inverse study to design the optimal shape and position for delta winglet vortex generators of pin-fin heat sinks. International Journal of Thermal Sciences 109 (2016) 374-385

[14] Babak Lotfi, Bengt Sundén b, Qiuwang Wang a, An investigation of the thermo-hydraulic performance of the smooth wavy fin-and-elliptical tube heat transfers utilizing new type vortex Generators. Applied Energy 162 (2016) 1282-1302

[15] Syaiful, Sugiri, G., Soetanto, M. F., \& Bae, M. W. 2016. Effect of concave rectangular winglet vortex generator on convection coefficient of heat transfer. In AIP Conference Proceedings (Vol. 1788, No. 1, p. 030025). AIP Publishing. 